\title{
Perfil do conhecimento dos produtores sobre a brucelose na saúde pública, em Redenção do Gurgueia - Piauí
}

\author{
Emanuella Soares Barbosa1, Johnny Iglesias Mendes Araujo ${ }^{2 *}$, Renata Rodrigues de \\ $\mathrm{Sá}^{3}$, Ana Lucia Alves da Silva ${ }^{4}$, Joniel Mendes de Araujo ${ }^{5}$ \\ ${ }^{l}$ Especialista em Educação Ambiental e Saúde Pública, Faculdade Evangélica Cristo Rei - FECR, Bom Jesus, \\ Piauí, Brasil.E-mail: manusaresb@outlook.com \\ ${ }^{2}$ Mestrando em Zootecnia pela Universidade Federal do Piauí, Campus professora Cinobelina Elvas - \\ UFPI/CPCE, Bom Jesus, Piauí, Brasil.E-mail: Johnny-iglesias@hotmail.com \\ ${ }^{3}$ Especialista em Educação Ambiental e Saúde Pública, Faculdade Evangélica Cristo Rei - FECR, Bom Jesus, \\ Piauí, Brasil.E-mail: renta@hotmail.com \\ ${ }^{4}$ Especialista em Docência e Supervisão Escolar, Instituto de Ensino Superior Múltiplo-IESM, Timon, \\ Maranhão, Brasil.E-mail: anaufpi@hotmail.com \\ ${ }^{5}$ Mestrando em Ciências Biológicas, Universidade Federal do Goiás, Campus Samambaia, Departamento de \\ Biologia, Goiânia, Goiás, Brasil.E-mail: niel.ma30@hotmail.com \\ *Autor para correspondência
}

RESUMO. A Brucelose é uma zoonose que causa grandes riscos à saúde pública e também grandes perdas econômicas na pecuária. É uma doença infecciosa causada pelas bactérias do gênero Brucella. A Brucelose nos bovinos recebeu atenção maior, por parte dos órgãos públicos, nos últimos anos, culminando com a criação do PNCEBT com campanhas de vacinação obrigatória para animais fêmeas de 3 a 8 meses de idade. Objetivou-se com esta pesquisa, verificar o conhecimento dos produtores rurais acerca da importância da brucelose para a saúde pública no município de Redenção do Gurgueia-PI. A pesquisa foi conduzida na cidade de Redenção do Gurgueia, localizado no sul do estado do Piauí. De acordo com os dados levantados junto aos pequenos produtores rurais foi possível observar que $45,5 \%$ dos produtores entrevistados sabem identificar os sinais da Brucelose, mas 54,5\% desconhecem os sinais clínicos da doença. Os resultados encontrados na pesquisa revelaram que, os produtores rurais do município de Redenção Gurguéia-PI, tem consciência dos danos que a Brucelose pode causar tanto à Saúde Animal quanto à Saúde Pública. Além, disso, foi possível perceber que a maior parte dos produtores preocupa-se e tem conhecimento básico também dos prejuízos que poderão ter, caso haja a introdução e difusão da doença em seus rebanhos.

Palavras chave: bactérias, bem-estar, doença infecciosa, tecidos linfóides, zoonose

\section{Profile of knowledge producers on brucellosis in public health in Redenção Gurgueia - Piauí}

\begin{abstract}
Brucellosis is a zoonotic disease that causes major risks to public health and also great economic losses in livestock. It is an infectious disease caused by bacteria of the genus Brucella. Brucellosis in cattle received greater attention by the public bodies in recent years, culminating in the creation of PNCEBT with compulsory vaccination campaigns for female animals from 3 to 8 months old. The objective of this research, verify the knowledge of farmers about the importance of brucellosis to public health in the municipality of Gurgueia-PI of the Redenção. The research was conducted in the town of Redenção of Gurgueia-PI, located in the southern state of Piauí. According to the data collected from the small farmers it was observed that $45.5 \%$ of respondents producers know how to identify the signs of Brucellosis, but $54.5 \%$ are unaware of the clinical signs of the disease. The results in the survey revealed that farmers in the
\end{abstract}


municipality of Redenção of Gurguéia-PI, is aware of the damage that Brucellosis can cause both the Animal Health as to public health. In addition, it was possible to see that most of the producers concerned and has also basic knowledge of the damage that may have, if there is the introduction and spread of the disease in their herds.

Keywords: bacteria, wellness, infectious disease, lymphoid tissues, zoonosis

\section{Introdução}

No Brasil, a grande preocupação, tanto de saúde animal quanto de consequente risco para a saúde pública, é a brucelose bovina, causada pela espécie B. abortus, devido ao tamanho e a distribuição do rebanho brasileiro, e pelas taxas de prevalência da infecção (Mathias, 2008). A brucelose nos animais provoca redução da produção leiteira, abortos, mortalidade de bezerros, esterilidade e perda de peso.

A B. abortus geralmente entra no organismo do hospedeiro pela mucosa oral ou nasal. Após a penetração na mucosa, as bactérias se multiplicam e são fagocitadas. Em geral, quando ocorre a entrada pela via digestiva, as tonsilas são um dos principais pontos de multiplicação do agente. Uma das características da infecção por Brucella $s p$ é o fato de a bactéria poder resistir aos mecanismos de destruição das células fagocitárias e sobreviver dentro de macrófagos por longos períodos.

Assim, as medidas de controle e erradicação devem ser baseadas na situação epidemiológica de cada região e vários fatores devem ser considerados para a escolha das melhores alternativas. O controle da brucelose apoia-se basicamente em ações de vacinação em massa de fêmeas (entre três e oito meses), e diagnóstico e sacrifício dos animais positivos. São também muito importantes as medidas complementares, que visam diminuir a dose de desafio (caso ocorra a exposição) bem como, é importante o controle de trânsitos para os animais de reprodução. Programas de desinfecção e utilização de piquetes de parição são iniciativas simples que trazem como resultado a diminuição da quantidade de brucelas vivas presentes no ambiente. Isso representa diminuir a dose de desafio, o que, por sua vez, significa aumentar os índices de proteção da vacina e diminuir a chance da bactéria infectar um novo animal suscetível (Brasil, 2005).

Portanto, objetivou-se com esta pesquisa, analisar o conhecimento dos produtores rurais acerca da importância da brucelose para a saúde pública no município de Redenção do Gurgueia.

\section{Material e Métodos}

A pesquisa foi conduzida na cidade de Redenção do Gurgueia, localizado no sul do estado do Piauí. O município localiza-se a uma latitude $09^{\circ} 29^{\prime} 12^{\prime \prime}$ sul e a uma longitude $44^{\circ}$ 35' 11' oeste, estando a uma altitude de 292 metros. Possui uma área de $2.468 \mathrm{~km}^{2}$, vegetação de cerrado e caatinga, e caracteriza-se por clima semi-árido. A sua temperatura anual média é de $36^{\circ} \mathrm{C}$ com precipitação anual de $502 \mathrm{~mm}$.

O levantamento foi desenvolvido no período compreendido entre os dias 25 de novembro a 2 de dezembro de 2014, onde foram previamente entrevistados 40 produtores do município. Nos questionários aplicados aos participantes da pesquisa serviu de padrão para todos os produtores onde se constatou de questões diretas, nas quais os mesmos respondiam conforme as peculiaridades de suas propriedades, avaliando as características de cada um com o objetivo de obter maior precisão no levantamento de dados. Foram elaboradas perguntas para relacionadas com as características gerais das propriedades e dos produtores, como: 01. Identificação do Produtor, nome; apelido; Idade; estado civil, Sexo e Escolaridade?; 02. Identificação do Imóvel: Área; Município e a Distância da sede?. Foram elaboradas perguntas relacionadas com o conhecimento sobre brucelose e cuidados sanitários como: 01. Você saberia identificar quais os sinais da brucelose? Sim ( ) Não ( ); 02. Você acha que a brucelose causa prejuízo ao produtor? Sim ( ) Não ( ); 03. Você sabe que a brucelose causa risco a saúde pública? Sim ( ) Não ( ); 04. Você sabe como combater ou prevenir a brucelose? Sim ( ) Não ( ); 05. Você acha que a campanha da vacinação contra brucelose é importante? Sim ( ) Não ( ); 06. Quando você vacina seu rebanho tem ajuda/assistência de um medico veterinário? Sim ( ) Não ( ); 06. Quando você vacina seu rebanho tem ajuda/assistência de um médico veterinário? Sim ( ) Não ( ); 07. Ao adquirir animais de outros municípios/estados, você exige o teste de brucelose? Sim ( ) Não ( ); 08. Na sua propriedade existem cuidados sanitários relativos à vermifugação? Sim ( ) Não ( ); 09. Existe 
orientação técnica na sua propriedade? Sim ( ) Não ( ); 10. Você realiza testes sorológicos regularmente nos animais da propriedade? Sim () Não ( ).

Os dados encontrados na pesquisa foram analisados quanto à percentagem de acordo com as respostas dadas pelos produtores rurais. A organização, tabulação e sumarização dos dados foram realizadas no Microsoft Excel 2010.

\section{Resultados e Discussão}

De acordo com os dados levantados junto aos pequenos produtores rurais foi possível observar conforme está na Tabela 1, que 45,5\% dos produtores entrevistados sabem identificar os sinais da Brucelose, mas 54,5\% dos entrevistados desconhecem os sinais clínicos da doença, muitas vezes por falta de medidas de conscientização e esclarecimento do que é a doença e os danos que ela causa, refletindo, portanto a falta de ações e programas de educação sanitária continuada, falhas no sistema de extensão rural, além da desinformação da população local, quanto aos riscos da doença.

Verificou-se ainda na Tabela 1 que, $100 \%$ dos produtores rurais entrevistados concordam que a Brucelose causa prejuízo ao criador/produtor, principalmente, devido a grandes perdas econômicas e riscos à saúde humana. Estimativas mostram ser a brucelose responsável pela diminuição de $25 \%$ na produção de leite e de carne e pela redução de $15 \%$ na produção de bezerros (Tabela 1). Mostram ainda que, em cada cinco vacas infectadas, uma aborta ou torna-se permanentemente estéril (Brasil, 2005). Pode assim afirmar que a brucelose é uma das maiores causas de prejuízo da criação de bovinos.

Os questionamentos sobre os cuidados sanitários relativos à vermifugação na Tabela 1 mostraram que $97 \%$ dos produtores fazem de uma a duas vezes ao ano vermifugação, e apenas $3 \%$ dos produtores não fazem. Poucos produtores adotam adequadas práticas de manejo sanitário, além disso, quando fazem é de maneira insatisfatória. Mesmo sendo $70 \%$ dos produtores assistidos de alguma forma, o manejo sanitário do rebanho não segue sequer o calendário oficial do MAPA, exceto pelo combate à febre aftosa, pois os dados relativos à brucelose e tuberculose (principais doenças dos rebanhos bovinos no Brasil) mostram o descaso por parte dos principais envolvidos, produtores e técnicos. É grande a necessidade de ajuda técnica, pessoas para orientar estes pequenos produtores

Tabela 1. Conhecimentos dos produtores rurais sobre a importância da Brucelose na Saúde Pública, no município de Redenção do Gurguéia-PI

\begin{tabular}{lcc}
\hline Questionários & Sim & Não \\
\hline 01.Você saberia identificar quais os sinais da Brucelose? & $45,5 \%$ & $54,5 \%$ \\
02.Você acha que a Brucelose causa prejuízo ao criador/produtor? & $100 \%$ & $00,0 \%$ \\
03.Você sabe que a Brucelose causa risco a saúde humana? & $62,5 \%$ & $37,5 \%$ \\
04.Você sabe como combater ou prevenir a Brucelose? & $43,4 \%$ & $56,6 \%$ \\
05.Você acha a campanha da vacinação da Brucelose importante? & $100 \%$ & $00,0 \%$ \\
06.Quando você vacina seu rebanho tem ajuda/assistência de um médico veterinário? & $8,45 \%$ & $91,55 \%$ \\
07.Ao adquirir animais de outros municípios/estados você exige o teste de Brucelose? & $00,0 \%$ & $100 \%$ \\
08.Na sua propriedade existem cuidados sanitários relativos a vermifugação? & $97 \%$ & $3 \%$ \\
09.Existe orientação técnica na sua propriedade? & $5 \%$ & $95 \%$ \\
10.Você realiza testes sorológicos regularmente nos animais da propriedade? & $00,0 \%$ & $100 \%$ \\
\hline
\end{tabular}

Quando questionados sobre os riscos que a Brucelose causa a saúde humana na Tabela 1, $62,5 \%$ dos produtores responderam que tem conhecimento sim dos riscos. E 37,5\% dos produtores responderam que não sabiam que a Brucelose causava risco a saúde humana. De acordo com Who (2006), as doenças transmitidas por alimentos, incluindo a brucelose, são causa de morbidade considerável nas populações em várias partes do mundo, tendo um grande impacto, principalmente em crianças e idosos. A doença é transmitida ao homem principalmente 
por meio da ingestão de leite ou queijo não pasteurizado já contaminado com uma das quatro espécies de Brucella considerada patogênicas para seres humanos (Memish \& Balkhy, 2004). Neste mesmo sentido Acha \& Szyfres (2001) afirmam que, a brucelose humana é também uma doença profissional que acomete agricultores, trabalhadores de matadouros, açougueiros e médicos veterinários. Nestes profissionais, a infecção normalmente ocorre pela manipulação de fetos e recém-nascidos, ou por contato com secreções e excreções vaginais e carcaças de animais contaminados.

No entanto, é uma a ameaça à saúde humana causada por B. abortus, assim como por outras espécies de Brucella, é provavelmente subestimada, considerando a inadequação dos serviços de comunicação e diagnóstico para brucelose humana (Poester et al., 2004).

$\mathrm{Na}$ Tabela 1, aos produtores quando foi perguntado se saberiam como combater ou prevenir a brucelose, 56,6\% dos produtores disseram que não saberiam, mas $43,4 \%$ dos produtores responderam que saberiam sim como combater e prevenir, através da vacinação e outros cuidados sanitários com o rebanho e instalações. Afirma Bailey (1987) que, o melhor programa de prevenção compõe-se de três partes distintas e importantes: higiene, vacinação e testes regulares. Técnicas usadas para controle de brucelose incluem: somente imunização, teste e retirada de animais infectados em conjunto com um programa de imunização e teste e retirada de animais infectados sem imunização (Hirsh \& Zee, 2003).

Quando questionados se achavam a campanha de vacinação da Brucelose importante, 100\% dos produtores responderam que sim, pois é através da vacinação que poderiam prevenir o rebanho (Tabela 1).

No que tange á assistência técnica prestada por médicos veterinários e técnicos agropecuários na Tabela 1, foi evidenciada a carência desta atividade haja vista que os produtores geralmente realizam a vacinação com o auxílio de outros criadores ou mesmo de familiares e amigos. Em outras campanhas de vacinação; porém, na campanha da Brucelose $100 \%$ tem ajuda especializada, por ser obrigatório que a mesma seja realizada por um profissional apto a realizar a vacinação no caso um médico veterinário.
Ao serem indagados se ao adquirir animais de outros estados/municípios exigiam o teste de Brucelose, $100 \%$ dos produtores relataram que nunca tiveram a preocupação de realizar estes testes Tabela 1. Durante as entrevistas foi esclarecido aos produtores que é de suma importância que sejam realizados os exames de brucelose todas as vezes que os mesmos forem adquirir animais de outros municípios/estados, para evitar que animais infectados entrem nos seus rebanhos. É da máxima importância, que a movimentação de animais de um lugar para o outro deva ser controlada em alto nível, uma vez que um programa rígido de erradicação em uma área pode ser anulado por causa de outro não eficaz na vizinhança (Blood \& Rodostits, 1991).

De acordo com os produtores entrevistados 95\% deles não recebem orientação técnica alguma em suas propriedades, sendo somente $5 \%$ deles que a tem. A orientação técnica é um importante meio de levar aos pequenos produtores as informações necessárias ao desenvolvimento e melhoramento de práticas agropecuárias, visando à geração de emprego e renda na propriedade rural e o bem-estar da família. Essa orientação é feita através de contatos direto com os produtores em forma de palestras, reuniões, seminários, demonstrações e outros meios que facilitem o entendimento por parte dos pequenos produtores (Emater- $\mathrm{Pb}$, 2007).

Quando ainda indagados se realizavam testes sorológicos nos seus rebanhos, $100 \%$ dos produtores responderam que não, pois só os realizariam se fossem obrigatórios. Responderam ainda que os custos seriam muito altos e que causariam prejuízo financeiro aos mesmos (Tabela 1).

\section{Conclusão}

De forma geral, de acordo com os resultados encontrados na pesquisa, podemos observar que os produtores rurais do município de Redenção Gurguéia - PI tem consciência dos danos que a Brucelose pode causar tanto à Saúde Animal quanto à Saúde Pública. Além, disso, foi possível perceber que a maior parte dos produtores preocupa-se e tem conhecimento básico também dos prejuízos que poderão ter, caso haja a introdução e difusão da doença em seus rebanhos.

Medidas preventivas devem ser tomadas já que a Brucelose é uma doença contagiosa e que 
contamina tanto humanos quanto animais. Fica claro que a vacinação é a melhor forma de se evitar a brucelose. Por isso, estão realizando a vacinação contra a Brucelose nas fêmeas de 03 a 08 meses de vida, conforme a campanha da Brucelose do Ministério da Agricultura. E se preocupam em fazer também outros tipos de prevenção, além de dedicar atenção a outros programas de vacinação de animais.

Para avançar no controle e obter a erradicação da enfermidade, se faz necessária à conscientização de todos os países, principalmente daqueles onde a produção bovina não é desenvolvida, pois estes geralmente são focos da doença.

\section{Referências Bibliográficas}

Acha, P. \& Szyfres, B. (2001). Zoonoses and Communicable Diseases Common to Man and Animals: Bacterioses and mycoses. 3. ed. Washington: Pan American Health Organization/World Health Organization 1: 398.

Bailey, J. W. (1987). Manual veterinário para criadores de gado. São Paulo: Organização Andrei Editora LTDA, 5, 311-321.

Brasil. Programa Nacional de Controle e Erradicação da Brucelose e Tuberculose Bovina. 9 p. Ministério da Agricultura e do Abastecimento, Departamento de Defesa Animal. 2005. Disponível em: <http://www.agricultura.gov.br/sda/dda/progr ama.htm.> Acesso em 07 de dezembro de 2014.

Blood, D. C. \& Rodostits, O. M. (1991). Clínica Veterinária. ed. Rio de Janeiro: Guanabara Koogan, 7,570-579.
Emater-escritório local (2007). Relatório de Atividades Anuais. Belém do Brejo do Cruz:PB p. 36.

Hirsh, D. C. \& Zee, Y. C. (2003). Microbiologia Veterinária. Rio de Janeiro: Guanabara Koogan, 191-195.

Mathias, L. A. (2008). Brucelose Animal e suas implicações em Saúde Pública. In: RAIB, 21, São Paulo. Palestra. São Paulo. O Biológico, 47-48.

Memish, Z. I. A. D. \& Balkhy, H. (2004). Brucelosis and International Travel. Journal of Travel Medicine, 11, 49-55.

Poester, F. P., Gonçalves, V.S. P., Lage, A. T. \& Bernard. (2004). Epidemiologia Aplicada: à luta colectiva contra as principais doenças animais transmissíveis. Lisboa: Fundação Calouste Gulbenkian, 676.

Who - World Health Organization. Corbel, M. J. (2006). (Org.). Brucellosis in humans and animals. Geneva: World Health Organization, 102.

\section{Article History:}

Received 23 August 2016

Accepted 10 September 2016

Available on line 17 October 2016

License information: This is an open-access article distributed under the terms of the Creative Commons Attribution License 4.0, which permits unrestricted use, distribution, and reproduction in any medium, provided the original work is properly cited. 